\title{
Toward adaptive deep brain stimulation for dystonia
}

\author{
Dan Piña-Fuentes, MD, ${ }^{1,2}$ Martijn Beudel, MD, PhD, ${ }^{2,3}$ Simon Little, MBBS, DPhil, ${ }^{4}$ \\ Jonathan van Zijl, MD, ${ }^{2}$ Jan Willem Elting, MD, PhD, ${ }^{2}$ D. L. Marinus Oterdoom, MD, ${ }^{1}$ \\ Martje E. van Egmond, MD, PhD, ${ }^{2}$ J. Marc C. van Dijk, MD, PhD, ${ }^{1}$ and \\ Marina A. J. Tijssen, MD, PhD²
}

Departments of ${ }^{1}$ Neurosurgery and ${ }^{2}$ Neurology, University Medical Center Groningen, University of Groningen; ${ }^{3}$ Department of Neurology, Isala Klinieken, Zwolle, The Netherlands; and ${ }^{4}$ Sobell Department of Motor Neuroscience and Movement Disorders, UCL Institute of Neurology, Queen Square, London, United Kingdom

\begin{abstract}
The presence of abnormal neural oscillations within the cortico-basal ganglia-thalamo-cortical (CBGTC) network has emerged as one of the current principal theories to explain the pathophysiology of movement disorders. In theory, these oscillations can be used as biomarkers and thereby serve as a feedback signal to control the delivery of deep brain stimulation (DBS). This new form of DBS, dependent on different characteristics of pathological oscillations, is called adaptive DBS (aDBS), and it has already been applied in patients with Parkinson's disease. In this review, the authors summarize the scientific research to date on pathological oscillations in dystonia and address potential biomarkers that might be used as a feedback signal for controlling aDBS in patients with dystonia.
\end{abstract}

https://thejns.org/doi/abs/10.3171/2018.5.FOCUS18155

KEYWORDS adaptive deep brain stimulation; dystonia; local field potentials; electromyography; low-frequency oscillations

A CCORDING to the latest expert consensus, dystonia is clinically defined as "a movement disorder characterized by sustained or intermittent muscle contractions causing abnormal, often repetitive, movements, postures, or both."2 Dystonia can be caused by numerous etiologies, including acquired and different biochemical, cellular, or genetic substrates. The similarity of the clinical dystonia phenotype, however, suggests a unifying common pathophysiological pathway at a functional or network level. ${ }^{4}$ A currently leading hypothesis on its neurophysiological basis is that dystonia is the result of abnormal activity in cortico-basal ganglia-thalamo-cortical (CBGTC) and cerebellar networks..$^{52}$ The treatment for the majority of dystonia subtypes only provides symptomatic relief, without addressing the underlying cause of the disease. Options currently available include oral medication (e.g., anticholinergic and antidopaminergic drugs, benzodiazepines, and baclofen), botulinum toxin (treatment of choice in focal dystonias), and deep brain stimulation (DBS). ${ }^{4}$

\section{DBS in Dystonia}

Given the limited efficacy and high prevalence of adverse effects associated with oral medication in generalized dystonia, DBS of the internal globus pallidus (GPi) has become the preferred therapy in this patient group. ${ }^{4}$ Several randomized controlled trials have demonstrated a sustained improvement in patients with (isolated) generalized dystonia following DBS, as shown by lower motor and functional scores on the Burke-Fahn-Marsden dystonia rating scale. ${ }^{29}$ After 5 years of DBS, generalized dystonia is reported to show a reduction in the Burke-Fahn-Marsden dystonia rating scale score of $42 \%-61 \% .{ }^{8}$ Furthermore, the health-related quality of life after DBS for dystonia improves significantly, by about $24 \%-51 \%$, among several

ABBREVIATIONS AA = agonist-antagonist; aDBS = adaptive deep brain stimulation; $C B G T C=$ cortico-basal ganglia-thalamo-cortical; $c$ DBS = continuous DBS; $E$ CoG = electrocorticography; EEG = electroencephalography; EMG = electromyography; GPi = internal globus pallidus; $L F P=$ local field potential; $P D=$ Parkinson's disease. SUBMITTED March 30, 2018. ACCEPTED May 11, 2018.

INCLUDE WHEN CITING DOI: 10.3171/2018.5.FOCUS18155. 
independent trials. ${ }^{27}$ DBS therapy has also been utilized in other types of dystonia when an adequate response to botulinum toxin therapy could not be achieved. ${ }^{24} \mathrm{~A}$ large, randomized clinical trial demonstrated that DBS is useful in medication-refractory cervical dystonia compared to sham stimulation, with a significant improvement of the Toronto Western Spasmodic Torticollis Rating Scale severity score ( $26 \%$ vs $6 \%$, respectively), 3 months after implantation. ${ }^{73}$

Despite its good effect, the exact mechanism of DBS in dystonia remains unclear, ${ }^{10}$ and clinical outcomes can differ from patient to patient, as well as among different subtypes of dystonia. ${ }^{8}$ Patients at an early stage of the disease and with less disability usually respond better to DBS. This is especially the case in patients with DYT1 mutations and tardive dystonia. In contrast, the response in other types of dystonia is less predictable, which makes the selection of appropriate candidates for DBS challenging. ${ }^{3}$

\section{Drawbacks of Current (Continuous) DBS}

More than 15 years of experience with DBS in dystonia has demonstrated the efficacy of the current model of continuous DBS (cDBS) once the optimal stimulation parameters have been achieved..$^{41}$ Nevertheless, there are still limitations in terms of efficacy and side effects related to cDBS. Due to limited knowledge of CBGTC and cerebellar networks in dystonia, the modification of electrical stimulation parameters in DBS is essentially heuristic, and DBS programming is based on clinical records and examination. In this process, the clinician starts with the conventional initial settings of the DBS system, delivering a constant current or voltage through the selected electrode(s). The settings are then adjusted in a trial-and-error process, based on the clinical response and the absence of adverse effects. ${ }^{50}$ However, an immediate response is often not possible to achieve, since it generally takes weeks to months to notice a perceptible change, especially in tonic dystonic components. ${ }^{53}$ For this reason, it can take up to several weeks to modify the initial parameters. ${ }^{30}$ In general, significant improvement can be expected approximately 3 months after the surgery, but it usually takes up to a year to achieve the maximum clinical effect. ${ }^{41}$ Another technical problem is the voltage required for stimulation in dystonia. While a mean of $3.0 \mathrm{~V}$ is usually effective to obtain an adequate clinical response in Parkinson's disease (PD) patients, with electrodes implanted either in the GPi or the subthalamic nucleus, ${ }^{47}$ the effective voltage in dystonia is more variable. It depends, among other things, on the type of dystonia, the area of the body affected, and the patient's tolerance of high voltages (due to the subsequent emergence of stimulation-related side effects), ranging from 2.2 up to $7.0 \mathrm{~V} .^{28}$ Therefore, non-rechargeable batteries need to be replaced more often, with a mean longevity of 28.1 months for dystonia compared with 47.2 months for PD. ${ }^{53}$ This not only increases the treatment costs, but it also exposes the patient to more surgical procedures, as well as their attendant risks.

Finally, there are significant side effects induced by cDBS in dystonia patients, such as dysarthria (in up to
$12 \%)^{29}$ and parkinsonism (13\%). ${ }^{70}$ Among patients with cranial-cervical dystonia treated with GPi DBS, $90 \%$ reported at least one motor symptom associated with parkinsonism, such as handwriting problems, difficulty with standing up from a chair, and gait disturbances. ${ }^{7}$ In line with this, a correlation has been described between the increase in GPi stimulation frequency and the development of bradykinesia. ${ }^{26}$

The appearance of these side effects after stimulation suggests that DBS interferes with both pathological activity in the CBGTC circuits $^{39}$ and physiological activity that helps to control voluntary movements..$^{9,29}$

To improve efficacy and limit side effects, much effort has been put into developing DBS systems that only stimulate when pathological activity and clinical symptoms are present ${ }^{39}$ Future DBS devices might be able to deliver electrical stimulation in response to pathological oscillations by increasing electrical current on demand-that is, only when, for example, the oscillatory power exceeds a threshold. ${ }^{46}$ This adaptive form of DBS (aDBS) has already been successfully applied in nonhuman primate models of $\mathrm{PD}^{56}$ by using the occurrence of cortical spikes as a biomarker. In patients with PD, there is also evidence of the effectiveness of aDBS. ${ }^{32,34,51,55}$ In these studies, the power of subcortical beta $(13-30 \mathrm{~Hz})$ oscillations, which correlate with bradykinesia and rigidity in PD, ${ }^{54}$ was used as a biomarker. The most important positive effects of human aDBS studies in PD were increased efficacy, energysaving properties, and potentially fewer side effects. This line of evidence strongly suggests that pathological oscillations can successfully be used as a biomarker for controlling DBS.

\section{Preparing the Way for aDBS in Dystonia Neural Oscillations as Biomarker}

Neural oscillations are part of the physiological components present in the regulatory pathways of voluntary movements and are potentially a means by which neuronal structures communicate among one another and with muscular units. ${ }^{61}$ The relationship of oscillations between two different sources can be addressed by means of coherence analysis, which indicates the degree of mutual dependence. ${ }^{12}$ Experiments carried out in healthy subjects have shown an increased coherence between cortical beta activity $(13-30 \mathrm{~Hz})$ and contralateral muscle discharges, respectively recorded with electroencephalography (EEG) and electromyography (EMG), suggesting that voluntary contractions are coupled with the physiological oscillatory activity of cortical neurons. . $^{12,60}$

In certain movement disorders, this physiological oscillatory activity is thought to be altered, since abnormal (pathological) oscillatory profiles have been detected. .,18,43 $^{-4}$ The use of subcortical beta oscillations as a biomarker for aDBS in PD was motivated by recordings of synchronized activity of large populations of neurons in the basal ganglia, known as local field potentials (LFPs). These LFPs can be recorded from the same DBS electrode contacts that deliver electrical stimulation. During a recording, LFPs are rapidly processed, and changes in power on a selected frequency band (e.g., beta range) are detected 

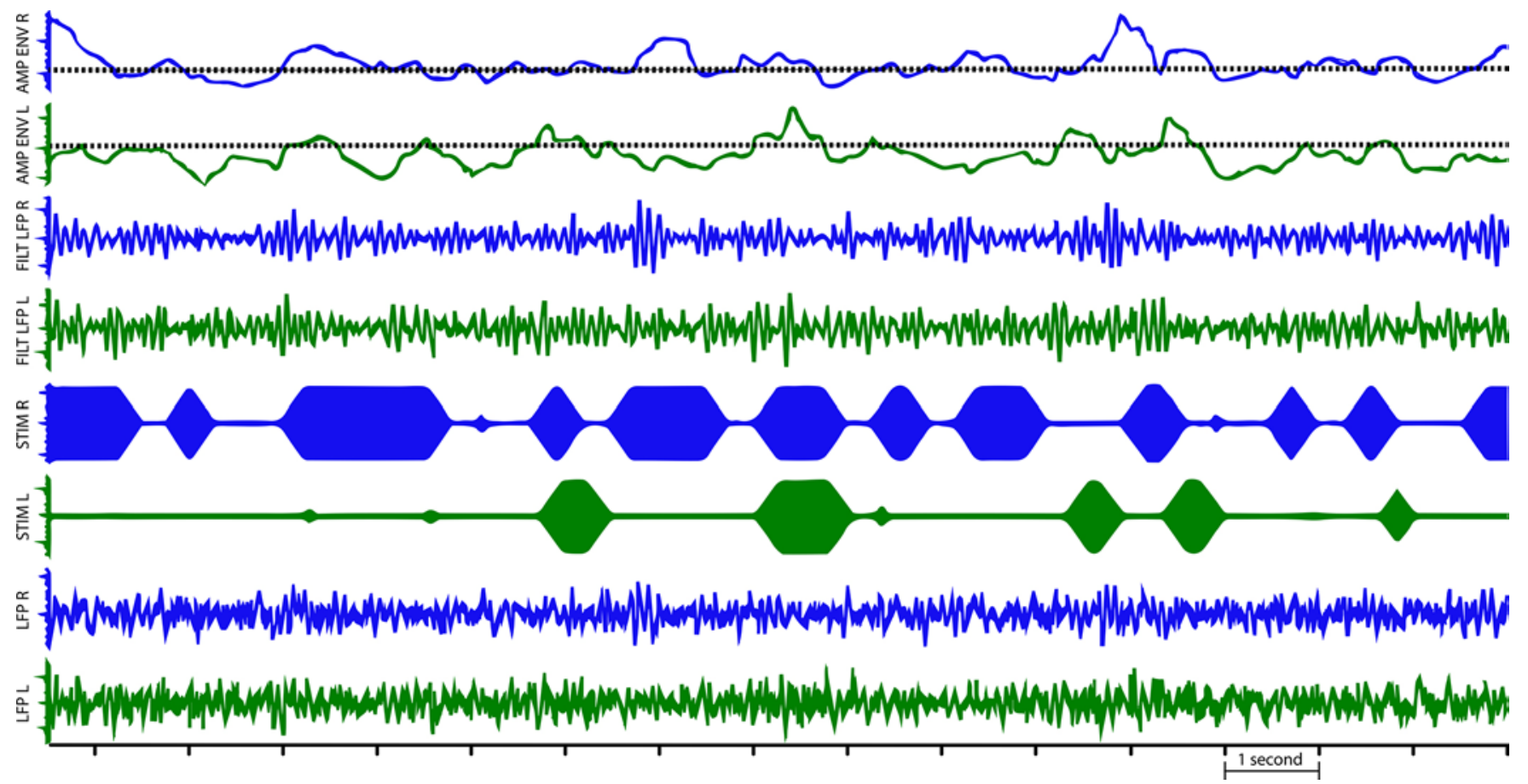

FIG. 1. Potential interface for aDBS using low-frequency oscillations. In this figure, the presence of low-frequency oscillations on an LFP is visualized and used for an adaptive stimulation algorithm. Raw signals (LFP $L$ and R) are dynamically recorded and filtered around the low-frequency peak registered (FILT LFP L and R). Afterwards, the filtered signal would be rectified, and an amplitude threshold would be set, in order to trigger the stimulation (STIM L and R) every time that an increment in low-frequency activity is detected. A brief delay in the activation of the stimulation would ensure that the stimulation is triggered only by actual increments of low-frequency activity and not by short-lived artifacts. AMP ENV = amplitude envelope of the rectified filtered signal; FILT LFP = LFP filtered around the low-frequency peak detected in order to visualize low-frequency oscillations embedded in the signal; $L$ = left; $R$ = right; $S T I M=$ channels representing stimulation amplitude.

through spectral analysis. The increase in frequency power triggers DBS in PD, which is continued until the power drops below a selected threshold..$^{25}$

One of the lessons learned from aDBS in PD patients is that the feedback signal of a biomarker needs to be both sensitive and specific. This means that the biomarker should correlate well in time with the severity of clinical symptoms (specificity) ${ }^{33}$ and that the signal detected should be powerful enough to be differentiated from artifacts-e.g., the noise caused by the stimulation itself (sensitivity). ${ }^{57}$

\section{Neural Oscillations in Isolated (Primary) Dystonia}

As discussed above, increased beta oscillations have been found in patients with PD and used as a biomarker for aDBS. To answer the question of whether it is possible to transfer aDBS from PD to dystonia, it is necessary to identify biomarkers for the latter (Fig. 1, Table 1). Several studies have addressed the presence of (pathological) oscillations in patients with isolated dystonia. LFP recordings have shown increased power in low frequencies (4-12 $\mathrm{Hz}$ ) in dystonia patients. ${ }^{64}$ Chen et al. demonstrated a positive correlation between pallidal low-frequency oscillations and muscle (EMG) activity in dystonia patients that was consistent among all contact pairs of the tested DBSelectrodes. ${ }^{9}$ In the same experiment, an additional correlation was found in the beta range $(13-30 \mathrm{~Hz})$, but this was not consistent among different contact pairs. Abnormal low-frequency oscillations have not only been found between GPi and EMG, but also in LFPs recorded in the subthalamic nucleus of dystonia patients ${ }^{17,45}$ and between different EMG signals. ${ }^{69}$ Directed transfer analyses suggest that this excessive oscillatory GPi activity is mostly driven from the GPi to the affected muscles. ${ }^{62}$

Furthermore, a sensorimotor modulation of GPi LFPs has been observed in response to active and passive movements, with a decreased LFP synchronization at $8-20 \mathrm{~Hz}$ and in dystonic involuntary muscle spasms with an increased activity in the range of $3-18 \mathrm{~Hz} .{ }^{35}$ This modulation of LFPs has also been observed in patients with an effective sensory trick (directing actions or movements to a specific part of their bodies where dystonia is present in order to alleviate their symptoms $\left.{ }^{2}\right) .{ }^{67}$ In these patients, a suppression of the abnormally synchronized activity in the range of $6-8 \mathrm{~Hz}$ and beta bands was observed during the performance of the sensory trick, indicating a peripheral regulation of the CBGCT oscillations. In summary, information from peripheral stimuli also influences the behavior of neural oscillations, at least to a certain degree.

A major finding that directly supports the use of low-frequency (4- to 12-Hz) oscillations as a biomarker for dystonia was described by Barow et al. ${ }^{5}$ In this study, increased low-frequency oscillations recorded from DBS electrodes of dystonia patients were significantly suppressed at the moment DBS was switched on, and they reemerged after 
TABLE 1. Potential biomarkers for aDBS in dystonia with their advantages, disadvantages, and challenges

\begin{tabular}{|c|c|c|c|}
\hline Biomarker & Advantages & Disadvantages & Further Questions \\
\hline $\begin{array}{l}\text { I. GPI LFPs of } 4-\text { to } 12-\mathrm{Hz} \text { magni- } \\
\text { tude/spectral power }\end{array}$ & $\begin{array}{l}\text { Most-studied oscillations. Correlated } \\
\text { w/ phasic dystonia. Direct measure- } \\
\text { ment of pathological network activity }\end{array}$ & $\begin{array}{l}\text { Not correlated w/ tonic dystonia. } \\
\text { Noise generated by stimula- } \\
\text { tion might interfere }\end{array}$ & $\begin{array}{l}\text { Evaluate the adequacy of the bio- } \\
\text { marker }\end{array}$ \\
\hline $\begin{array}{l}\text { II. Muscle activity (EMG) 4- to } \\
\text { 12-Hz magnitude/spectral power }\end{array}$ & $\begin{array}{l}\text { Coherent w/ LFPs. Direct measure- } \\
\text { ment of dystonic activity }\end{array}$ & $\begin{array}{l}\text { Additional device required for } \\
\text { EMG }\end{array}$ & $\begin{array}{l}\text { Investigate applicability of subcutane- } \\
\text { ous EMG in aDBS }\end{array}$ \\
\hline $\begin{array}{l}\text { III. Dystonic tremor (EMG) 4- to 12- } \\
\text { Hz magnitude/spectral power }\end{array}$ & $\begin{array}{l}\text { Potentially useful if tremor is the } \\
\text { predominant symptom. Direct mea- } \\
\text { surement of a clinical symptom }\end{array}$ & Nonspecific biomarker & $\begin{array}{l}\text { Develop algorithms capable of } \\
\text { increased specificity in detection of } \\
\text { dystonic tremor }\end{array}$ \\
\hline $\begin{array}{l}\text { IV. ECoG 4- to 12-Hz spectral } \\
\text { power }\end{array}$ & $\begin{array}{l}\text { Potential alternative for aDBS use. } \\
\text { High signal amplitude \& less stimu- } \\
\text { lation interference }\end{array}$ & $\begin{array}{l}\text { Subdural electrodes needed to } \\
\text { be placed. Still at an early } \\
\text { phase }\end{array}$ & $\begin{array}{l}\text { Elucidate which ECoG biomarkers } \\
\text { could be used as a feedback for } \\
\text { aDBS }\end{array}$ \\
\hline $\begin{array}{l}\text { V. Coherence between biomarkers } \\
\text { (e.g., LFP-EMG) }\end{array}$ & $\begin{array}{l}\text { Correlates two different sources of } \\
\text { pathological oscillations }\end{array}$ & $\begin{array}{l}\text { At least two different devices } \\
\text { are required. Lower temporal } \\
\text { resolution }\end{array}$ & $\begin{array}{l}\text { Examine whether coherence estima- } \\
\text { tion is sufficiently fast for adaptive } \\
\text { stimulation }\end{array}$ \\
\hline VI. EMG AA ratio/sum & $\begin{array}{l}\text { Identifies when dystonic activity is } \\
\text { present. Good time resolution }\end{array}$ & $\begin{array}{l}\text { At least two different devices } \\
\text { are required. Nonspecific. Not } \\
\text { predictive (rather reactive) }\end{array}$ & $\begin{array}{l}\text { Explore possibilities of using this } \\
\text { statistic to increase the specificity \& } \\
\text { time resolution of aDBS biomarkers }\end{array}$ \\
\hline
\end{tabular}

Common to all biomarkers is the need to establish their robustness across time and their reliability during brain states like sleep.

stimulation was switched off. Additionally, increased coherence from EEG LFPs and EMG LFPs within the 4- to $12-\mathrm{Hz}$ range was reduced after DBS stimulation. Another study showed that increased low-frequency activity in the cortex is normalized after applying DBS. ${ }^{40}$ These findings indicate that the application of high-frequency GPi DBS modulates the abnormally increased low-frequency activity. For these reasons, a paradigm for aDBS in dystonia based on the level of low-frequency oscillations seems plausible (Fig. 2).

The studies mentioned so far in this section included a varying degree of patients with different types of local, segmental, and generalized forms of isolated dystonia (both sporadic and genetic/familial) in their cohorts. For that reason, the specific roles of low-frequency oscillations in each form of isolated dystonia are currently unclear. Recently, a study that only included patients with cervical dystonia showed that the power of low-frequency oscillations in the dystonic GPi positively correlates with Toronto Western Spasmodic Torticollis Rating Scale scores, and an increased coherence is present between dystonic GPi and EMG signals in the low-frequency band. ${ }^{44}$ This gives a rationale for the employment of low-frequency oscillations as a biomarker for aDBS in this particular group.

Although several comparative studies have found increased subcortical low-frequency activity to be a characteristic of dystonia when compared to PD, ${ }^{17,64,75}$ this has not always been replicated..$^{65,68,74}$ The co-occurrence of dystonia and PD might, at least partially, explain this phenomenon. ${ }^{71}$ However, the exact role of (pathological) lowfrequency oscillations in dystonia is yet to be clarified.

\section{Neural Oscillations in Other Types of Dystonia}

Although virtually all neurophysiological studies described above have been carried out in patients with diverse forms of isolated dystonia, some studies have shown similar results for increased low-frequency oscillations in other subtypes of dystonia, indicating at least a partially shared common pathophysiology for all of them. Prominent 5- to $18-\mathrm{Hz}$ oscillations from the GPi and thalamus were recorded in a patient with acquired dystonia secondary to a cryptogenic stroke. ${ }^{72}$ Furthermore, studies based on LFP EMG and EMG-EMG coherence analysis have found an increased abnormal coherence in the lowfrequency range in patients with myoclonus-dystonia. ${ }^{15,16}$ These findings suggest that another potential biomarker to modulate the intensity of aDBS could include the lowfrequency common drive to motor units detected through EMG; detection of this could be technically possible thanks to the development of subcutaneous EMG registers that can transmit the information wirelessly to the DBS generator. ${ }^{38,59}$

\section{Phasic and Tonic Components of Dystonia}

While dystonia is usually composed of tonic (sustained) and phasic (rhythmic) abnormal movements, ${ }^{2}$ increased low-frequency oscillations have only, thus far, been correlated with the phasic components of dystonia, ${ }^{36,44}$ including the reduction of such abnormal oscillations after cDBS. ${ }^{5}$ With conventional cDBS, the clinical improvement of phasic and tonic components differs in time; phasic components improve faster (sometimes even immediately) following the application of DBS, whereas improvement in tonic components can take weeks to months. ${ }^{11}$ In contrast, when discontinuing stimulation, phasic components can recur rapidly, while tonic components recur in a more gradual manner. ${ }^{19}$ This temporal dissociation leads to the hypothesis that different pathophysiological mechanisms are involved. ${ }^{1}$ The rapid improvement seen in the phasic components is thought to be due to a direct DBS effect, whereas changes in tonic components are attributed to stimulation effects on neuronal plasticity. ${ }^{22}$ It has been observed that the benefits of DBS may remain after stimulation is discontinued, even after the 1-year follow- 


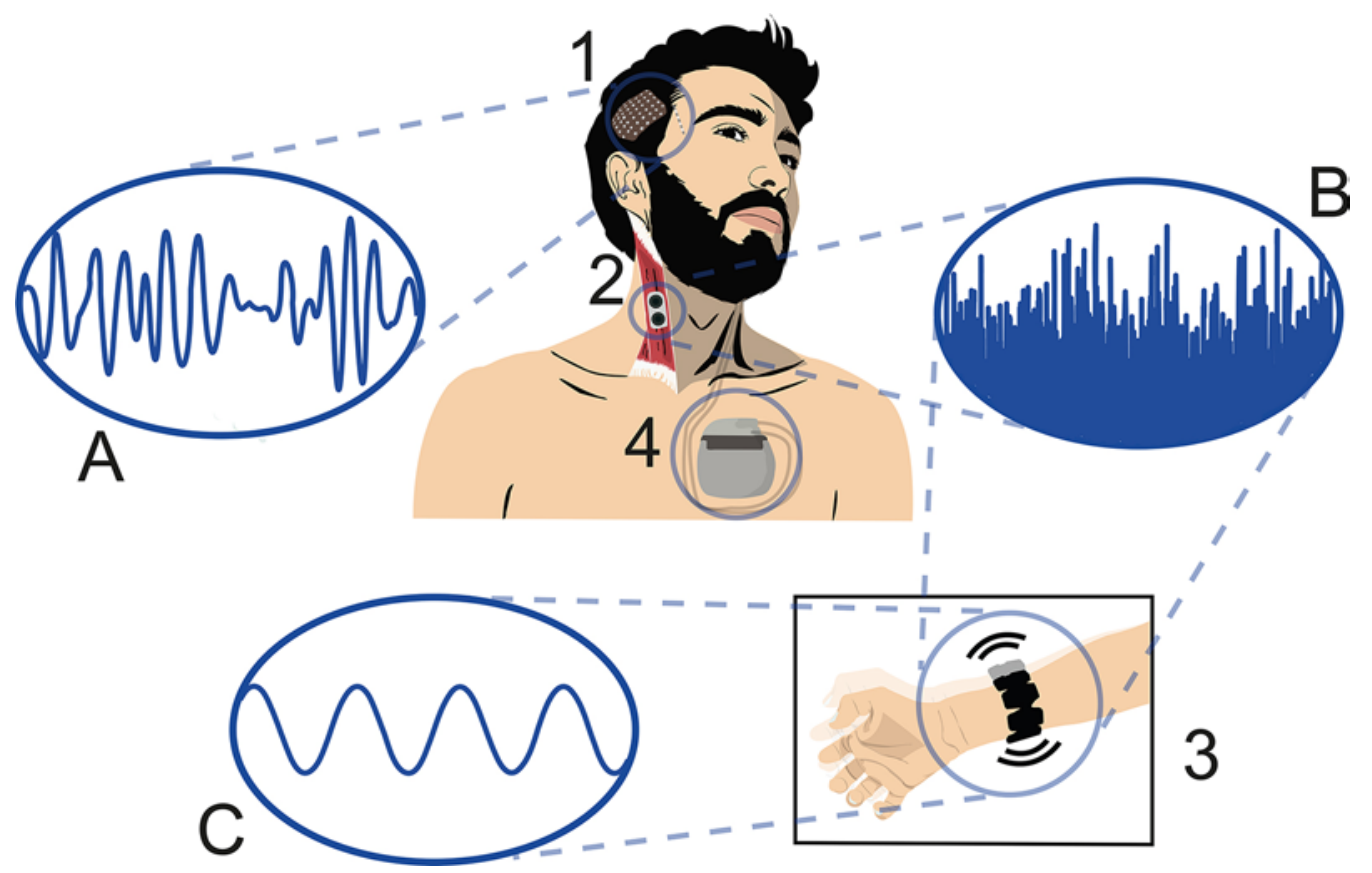

FIG. 2. Potential biomarkers and recording sites. Dystonic brain activity $(A)$ (e.g., increased low-frequency oscillations) can be recorded either in the form of local field potentials-from the electrodes used for stimulation or from electrodes placed on the cortical surface of the brain (electrocorticography) (1). Dystonic muscle activity $(B)$ can be recorded either from subcutaneous EMG (2) or through wearable devices (3), which could also detect dystonic tremor (C), thanks to integrated accelerometers. Signals can be instantaneously processed in the battery (4), to modulate stimulation according to the biomarker selected (to visualize a stimulation algorithm [see Fig. 1]). Copyright Dan Piña-Fuentes. Published with permission.

up period. ${ }^{20,58,66}$ This could imply that DBS produces a series of readjustments in CBGTC and cerebellar networks that persist after stimulation has ceased. It remains to be elucidated how aDBS might influence the tonic components of dystonia.

\section{Dystonic Tremor}

A specific component of phasic dystonia in which aDBS might be considered is the presence of dystonic tremor. The prevalence of tremor in patients with dystonia varies from $11 \%$ to $87 \%$ among studies. ${ }^{14}$ Lee et al. contrasted data of patients with task-specific primary bowing tremor (a task-specific tremor especially occurring in string musicians) with data obtained in matched healthy controls, revealing coherence between the coactivation of wrist antagonist muscles (measured with EMG) and tremor fluctuation (measured with accelerometers on the metacarpal-phalangeal joint of the index finger) in the low-frequency range only in the patient group..$^{31}$ Whereas this might indicate an influence of the dystonic oscillatory activity in dystonic tremor, more studies are required to elucidate this relationship. At present, when the tremor is the most disabling symptom, ${ }^{21}$ the ventral intermediate/ lateral thalamus is used as a primary target in dystonia patients. ${ }^{42}$

In a recent study, patients had an improvement of 77\% on clinical tremor scales after DBS of the ventrolateral thalamus. ${ }^{49}$ However, significant side effects also occurred, which raises the question of whether aDBS based on tremor amplitude/phase could be an alternative. How- ever, at this moment, the assessment of tremor using current accelerometers is still nonspecific, owing to the difficulties in distinguishing accelerometer signals resultant from voluntary movements. Advanced tremor-specific accelerometer computation paradigms to treat patients with PD are currently being explored, ${ }^{37}$ so in theory similar devices to assess dystonic tremor might be applied in the future. ${ }^{63}$

\section{Electrocorticography}

Electrocorticography (ECoG) recording is another neurophysiological tool that might be considered for aDBS. It uses electrodes implanted in the subdural space, giving a powerful spatial resolution of local cortical activity. One of the first ECoG studies on movement disorders used this technique to measure cortical LFPs in patients with PD, essential tremor, and (cranio-)cervical dystonia. ${ }^{13}$ In the resting state, the authors found a peak in motor cortex LFPs that occurred in the high-beta band for PD and in the low-beta band for dystonia and essential tremor. They also found an impaired cortical beta desynchronization related to movement, present in both motor and somatosensory areas. Low-frequency oscillations $(4-12 \mathrm{~Hz})$ were not analyzed in this study due to roll-off interference of the highpass filter in the recordings. Recently, the utility of ECoG to measure neural oscillations in the CBGCT network was addressed in a series of 189 patients (200 recordings) with movement disorders undergoing DBS surgery ${ }^{48}$ Some of the advantages of ECoG mentioned included higher-amplitude signaling, less DBS noise interference, and poten- 
tially a safe clinical profile (no significant adverse events added to the DBS procedure were reported in this study). These findings give rise to the potential use of ECoG to further investigate oscillations within the CBGTC network and, ultimately, find a potential biomarker for aDBS.

\section{Temporal Dynamics of Prospective Biomarkers}

One of the main questions that need to be answered before implementing aDBS in dystonia is what the temporal characteristics of the selected biomarker are. The latency and duration of the biomarkers mentioned (e.g., GPiLFPs), and how fast they react to electrical stimulation, should be investigated to determine how the aDBS system must be programmed and how well it can anticipate rather than react to the appearance of symptoms.

\section{Combining Neurophysiological Techniques}

In addition to single signals, the relation between oscillatory activity at two different sources, by means of coherence and/or other statistics might be used for aDBS. For example, LFP-EMG coherence or the EMG agonist-antagonist (AA) ratio might provide a more informative biomarker than a single-site recording. As mentioned before, increased coherence between LFP-EMG and EMG-EMG has been correlated with the severity of dystonic contractions. ${ }^{15,16}$ In relation to this, aDBS might be programmed based on the volatility in coherence. Nevertheless, to perform a "real-time" coherence analysis, the original signal has to be estimated over a finite period of time, limiting temporal resolution.

Besides coherence, other indicators of dystonic muscle activity can be obtained from EMG. This is based on the evidence that the co-contraction and overflow of AA muscles have been found on EMG measurements of dystonic patients. ${ }^{6}$ However, at present, an AA sum or AA ratio is not yet specific enough to differentiate signals of pathological contractions from voluntary contractions. ${ }^{23}$ In the future, evaluation of the predictive value of combined signals through machine learning may lead to greater specificity.

\section{Conclusions}

After years of successful application in dystonia, the potential of cDBS is still limited in terms of efficacy, side effects, and efficiency. Next to this, the current lack of neurophysiological parameters that can predict the individual clinical response of dystonia to DBS makes programming difficult. For these reasons, improvements in knowledge about the neurophysiological alterations underpinning dystonia and the emergence of DBS devices capable of simultaneously recording neural activity and providing stimulation should allow aDBS to be developed for the treatment of dystonia in the future. At present, 4- to $12-\mathrm{Hz}$ LFP oscillations appear to be the most promising candidate, but other neurophysiological signals (e.g., those from EMG and ECoG) and their interactions might also be suitable. However, many questions remain, such as the effects of microlesion effects, sleep, and medication on DBS recordings. Regardless of the source of the biomarker or biomarkers selected for aDBS, their volatility and robustness over time will have to be established. Critical too, most of the potential biomarkers described here relate to phasic aspects of dystonia, and therefore the more delayed response of more tonic dystonic elements to aDBS remains to be established.

\section{Acknowledgments}

We would like to thank Prof. Peter Brown for his advice.

This review was carried out thanks to public funds received from the Dutch Brain Foundation (Hersenstichting Nederland), the National Mexican Council of Science and Technology (CONACYT), and the University of Groningen/University Medical Center Groningen (RuG/UMCG). Z/14/Z).

S.L. is personally supported by the Wellcome Trust (105804/

\section{References}

1. Agnesi F, Johnson MD, Vitek JL: Deep brain stimulation: how does it work? Handb Clin Neurol 116:39-54, 2013

2. Albanese A, Bhatia K, Bressman SB, Delong MR, Fahn S, Fung VSC, et al: Phenomenology and classification of dystonia: a consensus update. Mov Disord 28:863-873, 2013

3. Andrews C, Aviles-Olmos I, Hariz M, Foltynie T: Which patients with dystonia benefit from deep brain stimulation? A metaregression of individual patient outcomes. J Neurol Neurosurg Psychiatry 81:1383-1389, 2010

4. Balint B, Bhatia KP: Dystonia: an update on phenomenology, classification, pathogenesis and treatment. Curr Opin Neurol 27:468-476, 2014

5. Barow E, Neumann WJ, Brücke C, Huebl J, Horn A, Brown P, et al: Deep brain stimulation suppresses pallidal low frequency activity in patients with phasic dystonic movements. Brain 137:3012-3024, 2014

6. Berardelli A, Rothwell JC, Hallett M, Thompson PD, Manfredi M, Marsden CD: The pathophysiology of primary dystonia. Brain 121:1195-1212, 1998

7. Berman BD, Starr PA, Marks WJ Jr, Ostrem JL: Induction of bradykinesia with pallidal deep brain stimulation in patients with cranial-cervical dystonia. Stereotact Funct Neurosurg 87:37-44, 2009

8. Brüggemann N, Kühn A, Schneider SA, Kamm C, Wolters A, Krause P, et al: Short- and long-term outcome of chronic pallidal neurostimulation in monogenic isolated dystonia. Neurology 84:895-903, 2015

9. Chen CC, Kühn AA, Hoffmann KT, Kupsch A, Schneider GH, Trottenberg T, et al: Oscillatory pallidal local field potential activity correlates with involuntary EMG in dystonia. Neurology 66:418-420, 2006

10. Chiken S, Nambu A: Mechanism of deep brain stimulation: inhibition, excitation, or disruption? Neuroscientist 22:313322, 2016

11. Chung M, Huh R: Different clinical course of pallidal deep brain stimulation for phasic- and tonic-type cervical dystonia. Acta Neurochir (Wien) 158:171-180, 2016

12. Conway BA, Halliday DM, Farmer SF, Shahani U, Maas P, Weir AI, et al: Synchronization between motor cortex and spinal motoneuronal pool during the performance of a maintained motor task in man. J Physiol 489 (Pt 3):917-924, 1995

13. Crowell AL, Ryapolova-Webb ES, Ostrem JL, Galifianakis NB, Shimamoto S, Lim DA, et al: Oscillations in sensorimotor cortex in movement disorders: an electrocorticography study. Brain 135:615-630, 2012

14. Defazio G, Conte A, Gigante AF, Fabbrini G, Berardelli A: Is tremor in dystonia a phenotypic feature of dystonia? Neurology 84:1053-1059, 2015

15. Foncke EMJ, Bour LJ, Speelman JD, Koelman JHTM, Tijssen MAJ: Local field potentials and oscillatory activity of the 
internal globus pallidus in myoclonus-dystonia. Mov Disord 22:369-376, 2007

16. Foncke EMJ, Bour LJ, van der Meer JN, Koelman JHTM, Tijssen MAJ: Abnormal low frequency drive in myoclonusdystonia patients correlates with presence of dystonia. Mov Disord 22:1299-1307, 2007

17. Geng X, Zhang J, Jiang Y, Ashkan K, Foltynie T, Limousin $\mathrm{P}$, et al: Comparison of oscillatory activity in subthalamic nucleus in Parkinson's disease and dystonia. Neurobiol Dis 98:100-107, 2017

18. Giannicola G, Marceglia S, Rossi L, Mrakic-Sposta S, Rampini P, Tamma F, et al: The effects of levodopa and ongoing deep brain stimulation on subthalamic beta oscillations in Parkinson's disease. Exp Neurol 226:120-127, 2010

19. Grips E, Blahak C, Capelle HH, Bäzner H, Weigel R, Sedlaczek O, et al: Patterns of reoccurrence of segmental dystonia after discontinuation of deep brain stimulation. J Neurol Neurosurg Psychiatry 78:318-320, 2007

20. Hebb MO, Chiasson P, Lang AE, Brownstone RM, Mendez I: Sustained relief of dystonia following cessation of deep brain stimulation. Mov Disord 22:1958-1962, 2007

21. Hedera P, Phibbs FT, Dolhun R, Charles PD, Konrad PE, Neimat JS, et al: Surgical targets for dystonic tremor: considerations between the globus pallidus and ventral intermediate thalamic nucleus. Parkinsonism Relat Disord 19:684-686, 2013

22. Herrington TM, Cheng JJ, Eskandar EN: Mechanisms of deep brain stimulation. J Neurophysiol 115:19-38, 2016

23. Hirai H, Miyazaki F, Naritomi H, Koba K, Oku T, Uno K, et al: On the origin of muscle synergies: invariant balance in the co-activation of agonist and antagonist muscle pairs. Front Bioeng Biotechnol 3:192, 2015

24. Horisawa S, Ochiai T, Goto S, Nakajima T, Takeda N, Kawamata T, et al: Long-term outcome of pallidal stimulation for Meige syndrome. J Neurosurg [epub ahead of print January 19, 2018. DOI: 10.3171/2017.7.JNS17323]

25. Hosain MK, Kouzani A, Tye S: Closed loop deep brain stimulation: an evolving technology. Australas Phys Eng Sci Med 37:619-634, 2014

26. Huebl J, Brücke C, Schneider GH, Blahak C, Krauss JK, Kühn AA: Bradykinesia induced by frequency-specific pallidal stimulation in patients with cervical and segmental dystonia. Parkinsonism Relat Disord 21:800-803, 2015

27. Jahanshahi M, Czernecki V, Zurowski AM: Neuropsychological, neuropsychiatric, and quality of life issues in DBS for dystonia. Mov Disord 26 (Suppl 1):S63-S78, 2011

28. Krauss JK, Yianni J, Loher TJ, Aziz TZ: Deep brain stimulation for dystonia. J Clin Neurophysiol 21:18-30, 2004

29. Kupsch A, Benecke R, Müller J, Trottenberg T, Schneider GH, Poewe W, et al: Pallidal deep-brain stimulation in primary generalized or segmental dystonia. N Engl J Med 355:1978-1990, 2006

30. Kupsch A, Tagliati M, Vidailhet M, Aziz T, Krack P, Moro E, et al: Early postoperative management of DBS in dystonia: programming, response to stimulation, adverse events, medication changes, evaluations, and troubleshooting. Mov Disord 26 (Suppl 1):S37-S53, 2011

31. Lee A, Tominaga K, Furuya S, Miyazaki F, Altenmüller E: Coherence of coactivation and acceleration in task-specific primary bowing tremor. J Neural Transm (Vienna) 121:739-742, 2014

32. Little S, Beudel M, Zrinzo L, Foltynie T, Limousin P, Hariz $\mathrm{M}$, et al: Bilateral adaptive deep brain stimulation is effective in Parkinson's disease. J Neurol Neurosurg Psychiatry 87:717-721, 2016

33. Little S, Pogosyan A, Kuhn AA, Brown P: Beta band stability over time correlates with Parkinsonian rigidity and bradykinesia. Exp Neurol 236:383-388, 2012

34. Little S, Pogosyan A, Neal S, Zavala B, Zrinzo L, Hariz M, et al: Adaptive deep brain stimulation in advanced Parkinson disease. Ann Neurol 74:449-457, 2013

35. Liu X, Wang S, Yianni J, Nandi D, Bain PG, Gregory R, et al: The sensory and motor representation of synchronized oscillations in the globus pallidus in patients with primary dystonia. Brain 131:1562-1573, 2008

36. Liu X, Yianni J, Wang S, Bain PG, Stein JF, Aziz TZ: Different mechanisms may generate sustained hypertonic and rhythmic bursting muscle activity in idiopathic dystonia. Exp Neurol 198:204-213, 2006

37. Malekmohammadi M, Herron J, Velisar A, Blumenfeld Z, Trager MH, Chizeck HJ, et al: Kinematic adaptive deep brain stimulation for resting tremor in Parkinson's disease. Mov Disord 31:426-428, 2016

38. Mendez I, Hansen BW, Grabow CM, Smedegaard EJL, Skogberg NB, Uth XJ, et al: Evaluation of the Myo armband for the classification of hand motions. IEEE Int Conf Rehabil Robot 2017:1211-1214, 2017

39. Meskers CGM, de Groot JH, de Vlugt E, Schouten AC: NeuroControl of movement: system identification approach for clinical benefit. Front Integr Nuerosci 9:48, 2015

40. Miocinovic S, Miller A, Swann NC, Ostrem JL, Starr PA: Chronic deep brain stimulation normalizes scalp EEG activity in isolated dystonia. Clin Neurophysiol 129:368-376, 2017

41. Miocinovic S, Somayajula S, Chitnis S, Vitek JL: History, applications, and mechanisms of deep brain stimulation. JAMA Neurol 70:163-171, 2013

42. Morishita T, Foote KD, Haq IU, Zeilman P, Jacobson CE, Okun MS: Should we consider Vim thalamic deep brain stimulation for select cases of severe refractory dystonic tremor. Stereotact Funct Neurosurg 88:98-104, 2010

43. Neumann WJ, Degen K, Schneider GH, Brücke C, Huebl J, Brown P, et al: Subthalamic synchronized oscillatory activity correlates with motor impairment in patients with Parkinson's disease. Mov Disord 31:1748-1751, 2016

44. Neumann WJ, Horn A, Ewert S, Huebl J, Brücke C, Slentz C, et al: A localized pallidal physiomarker in cervical dystonia. Ann Neurol 82:912-924, 2017

45. Neumann WJ, Huebl J, Brücke C, Ruiz MH, Kupsch A, Schneider GH, et al: Enhanced low-frequency oscillatory activity of the subthalamic nucleus in a patient with dystonia. Mov Disord 27:1063-1066, 2012

46. Neumann WJ, Staub F, Horn A, Schanda J, Mueller J, Schneider GH, et al: Deep brain recordings using an implanted pulse generator in Parkinson's disease. Neuromodulation 19:20-24, 2016

47. Odekerken VJJ, van Laar T, Staal MJ, Mosch A, Hoffmann CFE, Nijssen PCG, et al: Subthalamic nucleus versus globus pallidus bilateral deep brain stimulation for advanced Parkinson's disease (NSTAPS study): a randomised controlled trial. Lancet Neurol 12:37-44, 2013

48. Panov F, Levin E, de Hemptinne C, Swann NC, Qasim S, Miocinovic S, et al: Intraoperative electrocorticography for physiological research in movement disorders: principles and experience in 200 cases. J Neurosurg 126:122-131, 2017

49. Pauls KAM, Hammesfahr S, Moro E, Moore AP, Binder E, El Majdoub F, et al: Deep brain stimulation in the ventrolateral thalamus/subthalamic area in dystonia with head tremor. Mov Disord 29:953-959, 2014

50. Picillo M, Lozano AM, Kou N, Munhoz RP, Fasano A: Programming deep brain stimulation for tremor and dystonia: the Toronto Western Hospital algorithms. Brain Stimul 9:438-452, 2016

51. Piña-Fuentes D, Little S, Oterdoom M, Neal S, Pogosyan A, Tijssen MAJ, et al: Adaptive DBS in a Parkinson's patient with chronically implanted DBS: A proof of principle. Mov Disord 32:1253-1254, 2017

52. Prudente CN, Hess EJ, Jinnah HA: Dystonia as a network 
disorder: what is the role of the cerebellum? Neuroscience 260:23-35, 2014

53. Rawal PV, Almeida L, Smelser LB, Huang H, Guthrie BL, Walker HC: Shorter pulse generator longevity and more frequent stimulator adjustments with pallidal DBS for dystonia versus other movement disorders. Brain Stimul 7:345-349, 2014

54. Ray NJ, Jenkinson N, Wang S, Holland P, Brittain JS, Joint $\mathrm{C}$, et al: Local field potential beta activity in the subthalamic nucleus of patients with Parkinson's disease is associated with improvements in bradykinesia after dopamine and deep brain stimulation. Exp Neurol 213:108-113, 2008

55. Rosa M, Arlotti M, Ardolino G, Cogiamanian F, Marceglia S, Di Fonzo A, et al: Adaptive deep brain stimulation in a freely moving Parkinsonian patient. Mov Disord 30:1003-1005, 2015

56. Rosin B, Slovik M, Mitelman R, Rivlin-Etzion M, Haber SN, Israel Z, et al: Closed-loop deep brain stimulation is superior in ameliorating parkinsonism. Neuron 72:370-384, 2011

57. Rossi L, Foffani G, Marceglia S, Bracchi F, Barbieri S, Priori A: An electronic device for artefact suppression in human local field potential recordings during deep brain stimulation. J Neural Eng 4:96-106, 2007

58. Ruge D, Cif L, Limousin P, Gonzalez V, Vasques X, Coubes P, et al: Longterm deep brain stimulation withdrawal: clinical stability despite electrophysiological instability. J Neurol Sci 342:197-199, 2014

59. Ryapolova-Webb E, Afshar P, Stanslaski S, Denison T, de Hemptinne C, Bankiewicz K, et al: Chronic cortical and electromyographic recordings from a fully implantable device: preclinical experience in a nonhuman primate. J Neural Eng 11:016009, 2014

60. Salenius S, Portin K, Kajola M, Salmelin R, Hari R: Cortical control of human motoneuron firing during isometric contraction. J Neurophysiol 77:3401-3405, 1997

61. Schoffelen JM, Oostenveld R, Fries P: Neuronal coherence as a mechanism of effective corticospinal interaction. Science 308:111-113, 2005

62. Sharott A, Grosse P, Kühn AA, Salih F, Engel AK, Kupsch A, et al: Is the synchronization between pallidal and muscle activity in primary dystonia due to peripheral afferance or a motor drive? Brain 131:473-484, 2008

63. Shukla P, Basu I, Tuninetti D: Towards closed-loop deep brain stimulation: decision tree-based essential tremor patient's state classifier and tremor reappearance predictor. Conf Proc IEEE Eng Med Biol Soc 2014:2605-2608, 2014

64. Silberstein P, Kühn AA, Kupsch A, Trottenberg T, Krauss JK, Wöhrle JC, et al: Patterning of globus pallidus local field potentials differs between Parkinson's disease and dystonia. Brain 126:2597-2608, 2003

65. Starr PA, Rau GM, Davis V, Marks WJJ Jr, Ostrem JL, Simmons D, et al: Spontaneous pallidal neuronal activity in human dystonia: comparison with Parkinson's disease and normal macaque. J Neurophysiol 93:3165-3176, 2005

66. Stavrinou LC, Boviatsis EJ, Stathis P, Leonardos A, Panourias IG, Sakas DE: Sustained relief after discontinuation of DBS for dystonia: implications for the possible role of syn- aptic plasticity and cortical reorganization. J Neurol Surg A Cent Eur Neurosurg 73:175-178, 2012

67. Tang JKH, Mahant N, Cunic D, Chen R, Moro E, Lang AE, et al: Changes in cortical and pallidal oscillatory activity during the execution of a sensory trick in patients with cervical dystonia. Exp Neurol 204:845-848, 2007

68. Tang JKH, Moro E, Mahant N, Hutchison WD, Lang AE, Lozano AM, et al: Neuronal firing rates and patterns in the globus pallidus internus of patients with cervical dystonia differ from those with Parkinson's disease. J Neurophysiol 98:720-729, 2007

69. Tijssen MA, Marsden JF, Brown P: Frequency analysis of EMG activity in patients with idiopathic torticollis. Brain 123:677-686, 2000

70. Tisch S, Zrinzo L, Limousin P, Bhatia KP, Quinn N, Ashkan $\mathrm{K}$, et al: Effect of electrode contact location on clinical efficacy of pallidal deep brain stimulation in primary generalised dystonia. J Neurol Neurosurg Psychiatry 78:1314-1319, 2007

71. Tolosa E, Compta Y: Dystonia in Parkinson's disease. J Neurol 253 (Suppl 7):VII7-VII13, 2006

72. Tsang EW, Hamani C, Moro E, Mazzella F, Lozano AM, Yeh IJ, et al: Prominent 5-18 Hz oscillations in the pallidal-thalamic circuit in secondary dystonia. Neurology 78:361-363, 2012

73. Volkmann J, Mueller J, Deuschl G, Kühn AA, Krauss JK, Poewe W, et al: Pallidal neurostimulation in patients with medication-refractory cervical dystonia: a randomised, sham-controlled trial. Lancet Neurol 13:875-884, 2014

74. Wang DD, de Hemptinne C, Miocinovic S, Qasim SE, Miller AM, Ostrem JL, et al: Subthalamic local field potentials in Parkinson's disease and isolated dystonia: an evaluation of potential biomarkers. Neurobiol Dis 89:213-222, 2016

75. Weinberger M, Hutchison WD, Alavi M, Hodaie M, Lozano AM, Moro E, et al: Oscillatory activity in the globus pallidus internus: comparison between Parkinson's disease and dystonia. Clin Neurophysiol 123:358-368, 2012

\section{Disclosures}

The authors report no conflict of interest concerning the materials or methods used in this study or the findings specified in this paper.

\section{Author Contributions}

Conception and design: Piña-Fuentes, Beudel. Drafting the article: Piña-Fuentes, Beudel. Critically revising the article: Piña-Fuentes, Beudel, Little, van Dijk, Tijssen. Reviewed submitted version of manuscript: all authors. Approved the final version of the manuscript on behalf of all authors: Piña-Fuentes. Administrative/technical/material support: Piña-Fuentes. Study supervision: Beudel.

\section{Correspondence}

Dan Piña-Fuentes: University Medical Center Groningen, Groningen, The Netherlands.d.a.i.pina.fuentes@umcg.nl. 